\title{
Synthesis of Waste Cooking Oil Based Biodiesel via Ferric-Manganese Promoted Molybdenum Oxide / Zirconia Nanoparticle Solid acid Catalyst: Influence of Ferric and Manganese Dopants
}

\author{
Fatah H. Alhassan ${ }^{1,2 *}$, Umer Rashid ${ }^{3}$ and Yun Hin Taufiq-Yap ${ }^{1,2 *}$ \\ ${ }^{1}$ Catalysis Science and Technology Research Centre, Faculty of Science; Universiti Putra Malaysia, 43400 UPM Serdang, Selangor, Malaysia \\ ${ }^{2}$ Department of Chemistry, Faculty of Science; Universiti Putra Malaysia, 43400 UPM Serdang, Selangor, Malaysia \\ ${ }^{3}$ Institute of Advanced Technology, Universiti Putra Malaysia, 43400 UPM Serdang, Selangor, Malaysia
}

\begin{abstract}
The utilization of ferric-manganese promoted molybdenum oxide/zirconia (Fe-Mn- $\left.\mathrm{MoO}_{3} / \mathrm{ZrO}_{2}\right)$ (FMMZ) solid acid catalyst for production of biodiesel was demonstrated. FMMZ is produced through impregnation reaction followed by calcination at $600^{\circ} \mathrm{C}$ for $3 \mathrm{~h}$. The characterization of $\mathrm{FMMZ}$ had been done using X-ray diffraction (XRD), X-ray photoelectron spectroscopy (XPS), thermal gravimetric analysis (TGA), temperature programmed desorption of $\mathrm{NH}_{3}$ (TPD- $\mathrm{NH}_{3}$ ), transmission electron microscopy(TEM) and Brunner-Emmett-Teller (BET) surface area measurement. The effect of waste cooking oil methyl esters (WCOME's) yield on the reactions variables such as reaction temperature, catalyst loading, molar ratio of methanol/oil and reusability were also assessed. The catalyst was used to convert the waste cooking oil into corresponding methyl esters $(95.6 \% \pm 0.15)$ within $5 \mathrm{~h}$ at $200^{\circ} \mathrm{C}$ reaction temperature, $600 \mathrm{rpm}$ stirring speed, 1:25 molar ratio of oil to alcohol and $4 \% \mathrm{w} / \mathrm{w}$ catalyst loading. The reported catalyst was successfully recycled in six connective experiments without loss in activity. Moreover, the fuel properties of WCOME's were also reported using ASTM D 6751 methods.
\end{abstract}

Key words: ferric-manganese promoted molybdenum oxide/zirconia (FMMZ), waste cooking oil methyl esters (WCOMEs), crystallite size, Debye-Scherrer's relationship

\section{INTRODUCTION}

With decreasing fossil based-oil supply and outrageous increase in the cost of petroleum fuels, joined to the raise in green anxiety and recent financial decline, thus it would be vital to expand environmentally uncontaminated and power-competent skills for synthesizing maintainable outcomes $^{1)}$. Waste cooking oil methyl ester, a biofuel that can directly substitute for petroleum diesel fuels has gained much attention due to its renewable nature, green properties, calorific value, low toxic emission, carbon neutral, environmental benefits and their low cost ${ }^{2-4)}$. The costs of biofuel production would be more enhanced upon utilization of inexpensive raw materials e.g. spent cooking vegetable oil. Yet, the cheapest acidic oil incompatible for the preparation of biodiesel via liquid basic catalysts since this process is associated with a very complicated product purification protocol and serious impact to the environment ${ }^{5)}$.
Planning to reduce problems related to the liquid catalysis system a number of solid catalysis systems had been recommended ${ }^{6,7)}$. These systems are able to minimize the need for separation and washing protocol assist regeneration and reusability of the catalyst ${ }^{8)}$. Moreover, this group suggests efficient, environmental, industrial and financial gains which are significant factors towards enhanced and efficient procedure for preparation of biodiesel ${ }^{9)}$.

The growth of heterogeneous catalyst has been quite recent area of research in production of biodiesel. Generally, the heterogeneous catalysts have highest density of both basic and acidic Brönsted-Lowry and Lewis active centres further, this feature is recognized like enter parameter to their activity in the preparation of biodiesel ${ }^{10,11)}$. Additionally, catalysts incorporated tungsten-molybdenum metal had been comprehensively assessed in many operations such as isomerisation, cyclic alkenes, oxidation,

\footnotetext{
*Correspondence to: Fatah H. Alhassan, Catalysis Science and Technology Research Centre - Faculty of Science-Universiti Putra Malaysia - 43400 UPM Serdang Selangor, Malaysia

E-mail: abuohamid9090@gmail.com, taufiq@upm.edu.my

Accepted January 13, 2015 (received for review October 10, 2014)

Journal of Oleo Science ISSN 1345-8957 print / ISSN 1347-3352 online

http://www.jstage.jst.go.jp/browse/jos/ http://mc.manusriptcentral.com/jjocs
} 
alcohol dehydration and biodiesel synthesis ${ }^{12)}$. Moreover, the biodiesel production via various kinds of acidic heterogeneous systems such as molybdated supported on silica and molybdenum oxide doped zirconia has been reported by K. Jacobson et.al. ${ }^{11)}$. It was found that, the biodiesel yield achieved was 60 and 71\%, respectively. In our previous study ${ }^{13)}$, we developed Fe-Mn-W-Zr catalyst which showed high density of active sites, whereas in the current study, the incorporation of Fe-Mn dopant may increase the surface area and amount of active sites of Fe-Mn- $\mathrm{MoO}_{3} /$ $\mathrm{ZrO}_{2}$ catalyst.

As far as our knowledge, no effort was made till now on biodiesel synthesis utilizing ferric-manganese promoted molybdenum oxide/zirconia (FMMZ) catalyst. In this study the catalytic activity of FMMZ was assessed in a simultaneous synthesis of biodiesel employing spent acidic triglyceride. The characterization has been done using XRD, TPD$\mathrm{NH}_{3}$, TGA, BET, EDS, TEM and XPS Moreover, the influence of reaction factors including temperature of the process, loading of catalyst, time, spent oil/methyl alcohol ratio and recycling have also discussed. Efforts were also made to characterize the produced biodiesel and some of important fuel properties according to ASTM methods.

\section{EXPERIMENTAL}

\subsection{Chemicals and Materials}

Sample of waste cooking oil was obtained from local market - Serdang Malaysia. A total of $7.5 \mathrm{~kg}$ of oil was used for the optimization of biodiesel production process. The materials ferric nitrate nonahydrate, manganese nitrate tetra hydrate and ammonium molybdate tetra hydrate (99.0\%), zirconium oxy chloride and ammonium hydroxide $(28-30 \%)$ were obtained from (Sigma- Aldrich-Malaysia) and employed in the preparation of the catalyst ${ }^{13,14)}$.

\subsection{Pre-treatment of Feedstock}

For a completion of the simultaneous reaction and high yield of biodiesel from acidic oil the oil must be free of water and other impurities. Initially, the received feedstock was heated for $6 \mathrm{~h}$ at $105^{\circ} \mathrm{C}$ to remove water and debris of food. The free fatty acid (FFA) content was determined by a standard titration method ${ }^{14)}$.

\subsection{Characterization of Waste Cooking Oil}

Determinations of acid and saponification value of the waste cooking oil were carried out according to the standard AOCS methods ${ }^{15)}$.

\subsection{Catalyst Preparation}

$7.5 \mathrm{~g}$ of hydrate zirconyl oxychloride $\mathrm{ZrOCl}_{2}$ were dissolved in about $150 \mathrm{ml}$ of deionised water, drop wise addition of $3.95 \mathrm{gm}$ of a $30 \%$ aqueous solution of ammonia led to precipitation; as much of the ammonia solution was added as was necessary to reach a $\mathrm{pH}$ in range of (9-10). The precipitate was aging for $12 \mathrm{~h}$ filtered by vacuum, washed several times until a negative test of chloride ion and dried for about $24 \mathrm{~h}$ at $120^{\circ} \mathrm{C}$.

$\mathrm{Fe}\left(\mathrm{NO}_{3}\right)_{3} \cdot 9 \mathrm{H}_{2} \mathrm{O}(1.728 \mathrm{~g}), \mathrm{Mn}\left(\mathrm{NO}_{3}\right)_{2} \cdot 4 \mathrm{H}_{2} \mathrm{O}(0.3645 \mathrm{~g})$ and ammonium molybdate tetra hydrate $(5.481 \mathrm{~g})$ were dissolved in about $150 \mathrm{ml}$ of deionised water in amounts corresponding to the desired stoichiometry and the solution was added drop wise under vigorous Stirring to zirconium oxyhydroxide solution and the mixture was left under vigorous stirring at room temperature for $4 \mathrm{~h}$. The mixture is then dried at $120^{\circ} \mathrm{C}$ for $12 \mathrm{~h}$ then calcined at $600^{\circ} \mathrm{C}$ for 3 $h^{13)}$.

\subsection{Catalyst Characterization}

The powder X-ray diffraction analysis was carried out using a Shimadzu diffractometer model XRD 6000. The diffractometer employing $\mathrm{Cu}-\mathrm{K} \alpha$ radiation to generate diffraction patterns from powder crystalline samples at ambient temperature. The $\mathrm{Cu}-\mathrm{K} \alpha$ radiation was generated by Philips glass diffraction X-ray tube broad focus $2.7 \mathrm{~kW}$ type. The crystallite size D of the samples was calculated using the Debye-Scherrer's relationship ${ }^{16,17)}$.

$$
\mathrm{D}=0.9 \lambda /(\mathrm{B} \cos \theta)
$$

Where $\mathrm{D}$ is the crystallite size, $\lambda$ is the incident $\mathrm{X}$-ray wavelength, $\beta$ is the full width at half-maximum, and $\theta$ is the diffraction angle.

XPS spectra were obtained using a modified AXIS ULTRA DLD (KRATOS) photoelectron spectrometer equipped with a hemispherical analyzer. For excitation, AlKa $(1486.6 \mathrm{eV})$ radiation was used. The analyzer was operated in the fixed analyzer transmission mode at $40 \mathrm{eV}$ pass energy. The X-ray gun was operated at $4 \mathrm{~mA}$ emission current and $15 \mathrm{kV}$ acceleration voltages. Samples were pretreated under vacuum $\left(1 \times 10^{-9}\right.$ Torr $)$ at $22 \pm 2$ for $2 \mathrm{~h}$ before measurements. The base pressure of the analyzer chamber was $1 \times 10^{-9}$ Torr; during data collection the pressure was still always $<1 \times 10^{-9}$ torr. Binding energy (BE) corresponding to C 1s,Mo 3d, Zr 3d, Fe 2p, Mn 2p and O 1s were measured. All binding energies are relative to $\mathrm{C} 1 \mathrm{~s}$ peak taken as $284.5 \mathrm{eV}$.

The TGA analysis was done on a Mettler Toledo TG-SDTA apparatus (Pt crucibles, Pt/Pt- Rh thermocouple) with the purge gas (nitrogen) flow rate of $30 \mathrm{ml} \mathrm{min}^{-1}$ and the heating rate of $10^{\circ} \mathrm{C} \mathrm{min}^{-1}$ from room temperature to $1000^{\circ} \mathrm{C}$.

The acidity of the catalyst was performed by temperature programmed desorption using $\mathrm{NH}_{3}$ as probe molecule. The TPD- $\mathrm{NH}_{3}$ experiment was conducted using a Thermo Finnigan TPDRO 1100 apparatus equipped with a thermal conductivity detector. Approx $0.1 \mathrm{~g}$ of catalyst was placed in the reactor treated under $150^{\circ} \mathrm{C}$ for $15 \mathrm{~min}$ in $\mathrm{N}_{2}(20 \mathrm{ml}$ 
min ${ }^{-1}$ ) and $\mathrm{NH}_{3}$ in helium gas was ramped at $1^{\circ} \mathrm{C} \min ^{-1}$ for 60 min. the purging with $\mathrm{N}_{2}$ was done at room temperature for 45 min to remove $\mathrm{NH}_{3}$ in the gas phase. The analysis of $\mathrm{NH}_{3}$ desorption was then carried out between $50^{\circ} \mathrm{C}$ and $900^{\circ} \mathrm{C}$ under helium flow $\left(15^{\circ} \mathrm{C} \mathrm{min}^{-1}, 20 \mathrm{ml} \mathrm{min}^{-1}\right)$ and detected by a thermal conductivity detector.

The elemental chemical composition of the prepared ferric-manganese promoted molybdenum oxide/zirconia acid catalyst was determined by Shimadzu X-ray fluorescence (XRF) with a Rayny EDX-720 spectrometer.

TEM (Hitachi H-7100, Japan) was also used to examine the crystal shape. For TEM analysis the powder was dispersed in deionized water dropped onto carbon-cover copper grids placed on a filter paper and dried at room temperature.

The BET surface area of the catalysts was achieved using Brunauer-Emmer-Teller (BET) method with nitrogen adsorption at $-196^{\circ} \mathrm{C}$. Analysis was conducted using a Thermo Fisher Scientific S.p.A (model: SURFER ANALYZER) nitrogen adsorption-desorption analyzer.

\subsection{Simultaneous Reaction of Waste Cooking Oil}

The simultaneous esterification and transesterification reaction of waste cooking oil containing $17.5 \%$ free fatty acids was done using prepared ferric-manganese promoted molybdenum oxide/zirconia acid catalyst in BERGHOF (250 $\mathrm{mL}$ ) high pressure laboratory reactor (Fig. 1). A different amount of catalyst, methanol and $25 \mathrm{~g}$ oil in each were added to the reactor. The reaction was started by stirring at $600 \mathrm{rpm}$ and heated to specified temperature and time. Then, the reaction mixture was cooled to room temperature and the catalyst has been separated by centrifuge (Kubota 4200) at rpm 350 for $20 \mathrm{~min}^{13)}$. Furthermore, the excess methanol is removed via rotary evaporator.

\subsection{Product Analysis}

The biodiesel produced was determined by gas chromatography a Shimadzu(GC-14B) with Flame Ionization Detector (FID) detector equipped with Rtx-65 capillary column $(30 \mathrm{~m} \times$ diameter $0.25 \mathrm{~mm} \times 0.25 \mu \mathrm{m})$. Helium was used as carrier gas with the initial oven temperature at $100^{\circ} \mathrm{C}$ held for $0.5 \mathrm{~min}$ and subsequently increased to $260^{\circ} \mathrm{C}$ (hold $10 \mathrm{~min}$ ) at $20^{\circ} \mathrm{C} / \mathrm{min}$. Temperatures of the injector and detector were set at $250^{\circ} \mathrm{C}$ and $280^{\circ} \mathrm{C}$, respectively. In each run, $1 \mu \mathrm{L}$ of the sample was injected into the column. Methyl heptadecanoate was used as the internal standard to calculate the yield of WCOME's. The yield of ester was determined by the following Eq. ${ }^{18,19)}$.

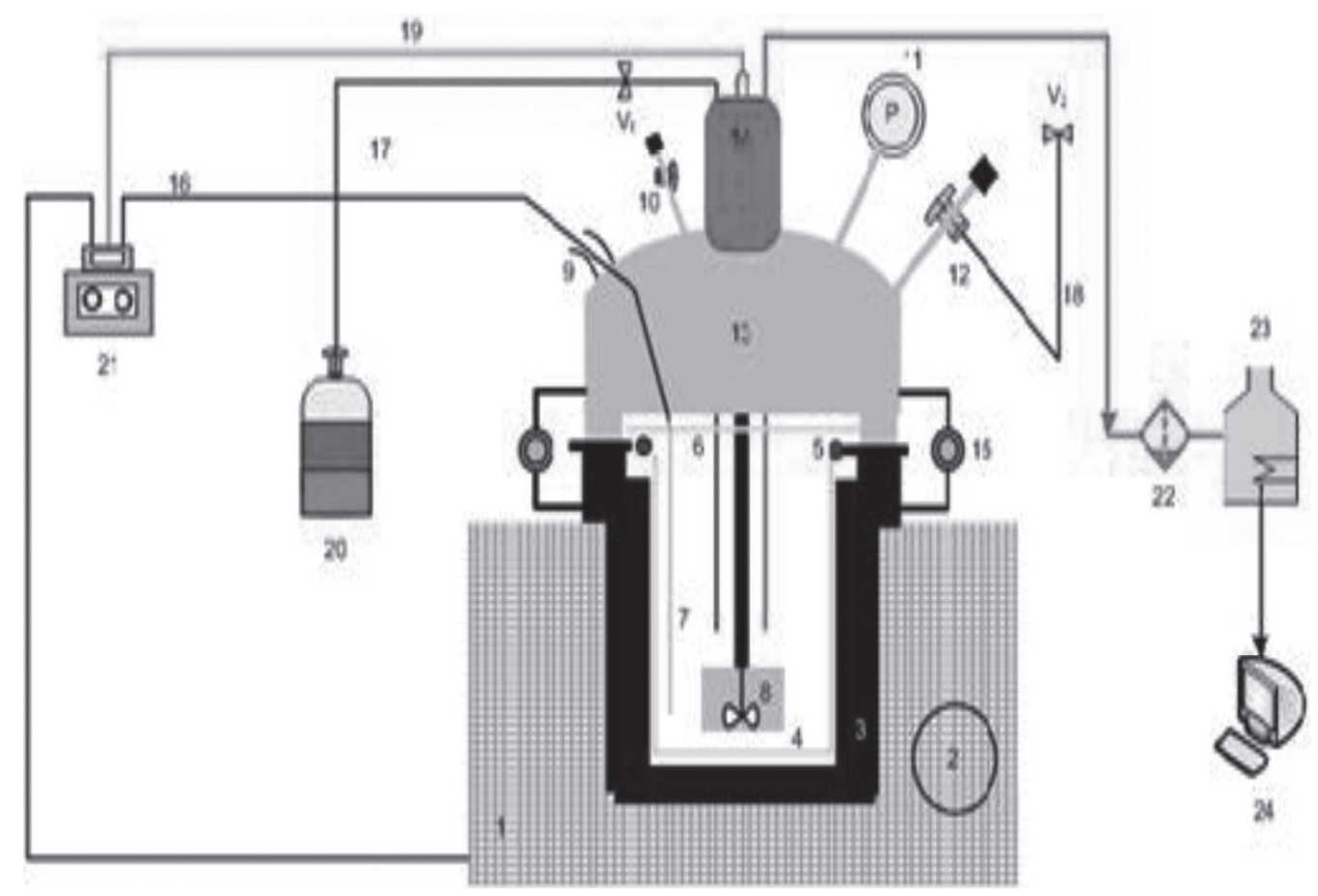

Fig. 1 The reactor assembly for transesterification reaction.

1-Heater, 2-Safety temperature controller, 3-Reactor vessel, 4-PTFE insert, 5-PTFE O-ring, 6-PTFE lid lining, 7-K-type thermocouple, 8-TPFE covered stirrer, 9-Temperature regulation, 10-Standard fittings $\left(\mathrm{N}_{2}\right)$, 11-Pressure measurement, 12-special fittings, 13-Reactor lid, 14-Stirring, 15-Closure, 16-Thermocouple connector line, 17-Stainless steel line (input), 18-Stainless steel line (output), 19, Stirring connector line, 20, Temperature controller line, 21-Controller, 22-Centrifuge, 23- Rotary evaporator, 24- Gas chromatography. 
Yield of WCOMEs $(\%)=($ Total weight of methyl esters $\times 100) \div$ Total weight of oil sample

\subsection{Catalyst Reusability and Leaching Tests}

The catalyst separated from the reaction mixture through centrifuge at $350 \mathrm{rpm}$ for $20 \mathrm{~min}$. and then filtration was initially washed with hexane to remove non-polar compounds such as methyl esters on the surface. Moreover, the catalyst was washed with methanol to remove polar compounds such as glycerol and finally dried at $120^{\circ} \mathrm{C}$ for six $\mathrm{h}$. The leaching of the catalyst into the reaction mixture was evaluated with a Rayny EDX-720 spectrometer.

\subsection{Fuel Properties}

The fuel properties of the WCOME's were analysed subsequently by ASTM methods: cloud point (ASTM D2500), pour point (ASTM D97), kinematic viscosity (ASTM D445), flash point (ASTM D93) and density (ASTM D5002). Triplicate determinations were carried out for every experiment and the data are presented as mean \pm standard deviation.

\section{RESULTS AND DISCUSSION}

\subsection{Characterization of $\mathrm{Fe}-\mathrm{Mn}-\mathrm{MoO}_{3} / \mathrm{ZrO}_{2}$ Catalyst}

The powder X-ray pattern of the Fe-Mn- $\mathrm{MoO}_{3} / \mathrm{ZrO}_{2}$ (FMMZ) catalyst calcined at $600^{\circ} \mathrm{C}$ for $3 \mathrm{~h}$ is presented in Fig. 2. The XRD pattern of Fe-Mn- $\mathrm{MoO}_{3} / \mathrm{ZrO}_{2}$ shows a mixture of both tetragonal and monoclinic crystal system.
Nevertheless, sharp diffraction lines at $2 \theta=30.1,34.8^{\circ}$, $50.1^{\circ}$ and $60.0^{\circ}$ are due to the tetragonal form of zirconia (JSPDS file No: 00-050-1089 $\mathrm{ZrO}_{2}$ ). While the diffraction peaks at $2 \theta=23.4,32.5^{\circ}, 43.1^{\circ}$ and $57.1^{\circ}$ are attributed to the monoclinic phase of zirconia (JSPDS file No: 01-079$\left.0764 \mathrm{ZrO}_{2}\right)$. Reflections lines appeared at $2 \theta=25.7$ and $27.3^{\circ}$ are due to the molybdenum oxide ${ }^{20,21)}$. In addition, the strength of the peak matching the monoclinic phase is lower in the ferric-manganese promoted molybdenum oxide/zirconia suggesting the stabilization of the tetragonal phase. The absence of characteristic peaks matching to $\mathrm{Fe}_{2} \mathrm{O}_{3}$ and $\mathrm{MnO}$ imply that the metal oxides were found in the composition of hard solution or it is well distributed in surface of zirconia. The dispersion of $\mathrm{Fe}_{2} \mathrm{O}_{3}$, $\mathrm{MnO}$ particles and $\mathrm{MoO}_{3}$ assisted stabilization of zirconia tetragonal crystal system $^{21}$. Clearly, Molybdenum resists transformation of zirconia tetragonal crystal system to the monoclinic ones. Yet, there was a research study regarding yttrium and lanthanum oxide as stabilizer for zirconia tetragonal phase via improvement of the particle-border and consequently enhances the surface area of the catalyst ${ }^{20-22)}$.

To identify the influence of Molybdenum oxide amount on the FMMZ crystal system the size of zirconia and FMMZ were obtained via Debye-Scherrer's equation. The addition of Molybdenum oxide has been related to the size reduction which changes from 25.5 to $10.0 \mathrm{~nm}$ for zirconia $(\mathrm{Z})$ and Fe-Mn- $\mathrm{MoO}_{3} / \mathrm{ZrO}_{2}(\mathrm{FMMZ})$, respectively. This may be coupled with the Molybdenum oxide which stays bounded to the catalyst surface thus reduce the enlargement of zirconia particles in agreement therefore with the oxides of transition metals, such as titania and stannia ${ }^{23)}$. Reduction in the size of crystallite could be illustrated with concept

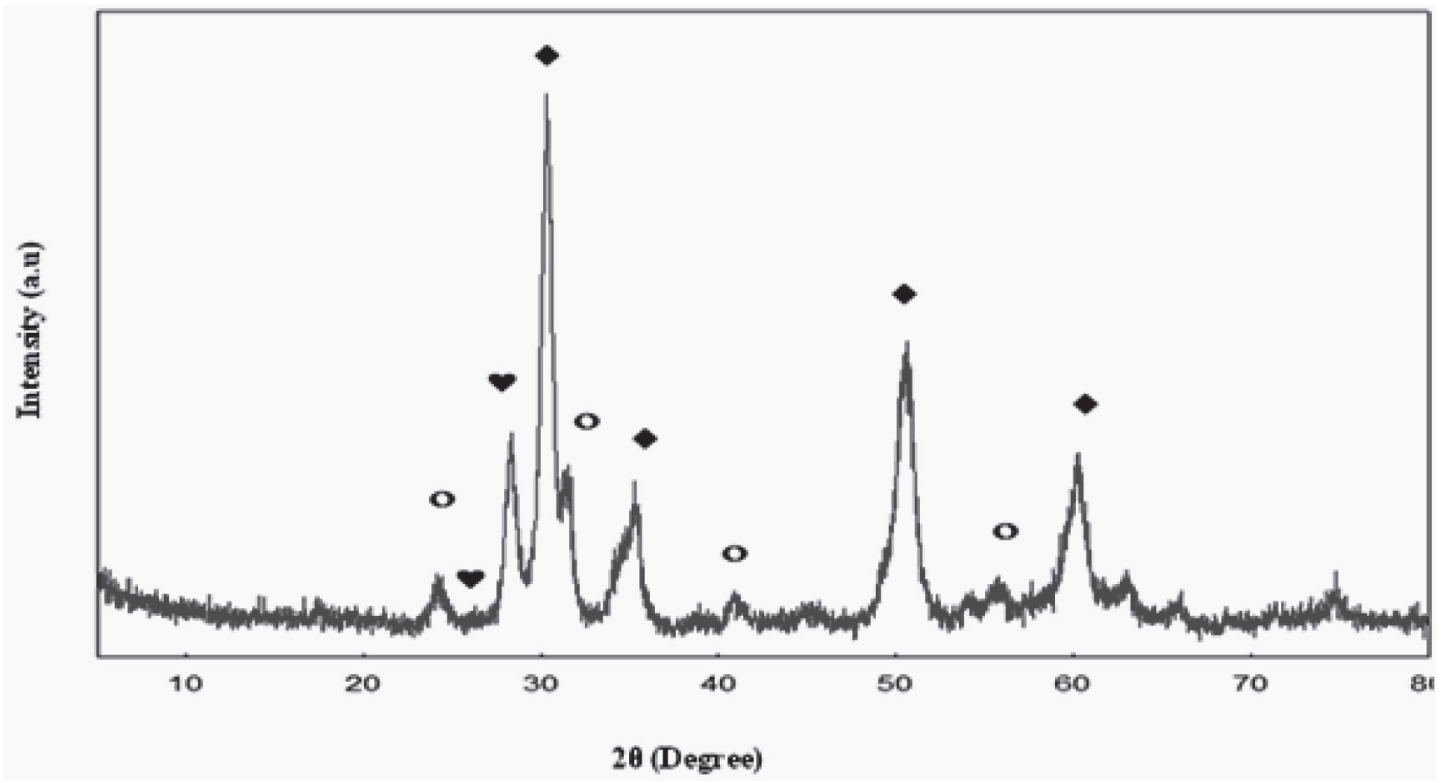

Fig. 2 XRD patterns of Fe-Mn- $\mathrm{MoO}_{3} / \mathrm{ZrO}_{2}(\mathrm{FMMZ})$ catalyst calcined at $600^{\circ} \mathrm{C}$ for $3 \mathrm{~h}$. (O) monoclinic phase; ( $\left.\diamond\right)$ tetragonal phase of zirconia and $(\boldsymbol{V}) \mathrm{MoO}_{3}$ Phase. 
Table 1 The influence of Ferric and Mn-dopants on the catalytic activity of $\mathrm{Fe}-\mathrm{Mn}-\mathrm{MoO}_{3} / \mathrm{ZrO}_{2}$.

\begin{tabular}{lccc}
\hline \multicolumn{1}{c}{ Catalyst } & Ester yield $(\%)$ & BET $\left(\mathrm{m}^{2} / \mathrm{g}\right)$ & Density of active sites $(\mu \mathrm{mol} / \mathrm{g})$ \\
\hline $\mathrm{ZrO}_{2}$ & $48.6 \pm 1.14$ & 34.5 & 630.4 \\
$\mathrm{MoO}_{3} / \mathrm{ZrO}_{2}$ & $73.0 \pm 0.25$ & 37.0 & 1144.0 \\
$\mathrm{Fe}-\mathrm{Mn}-\mathrm{MoO}_{3} / \mathrm{ZrO}_{2}$ & $95.6 \pm 0.15$ & 49.5 & 2411.0 \\
\hline
\end{tabular}

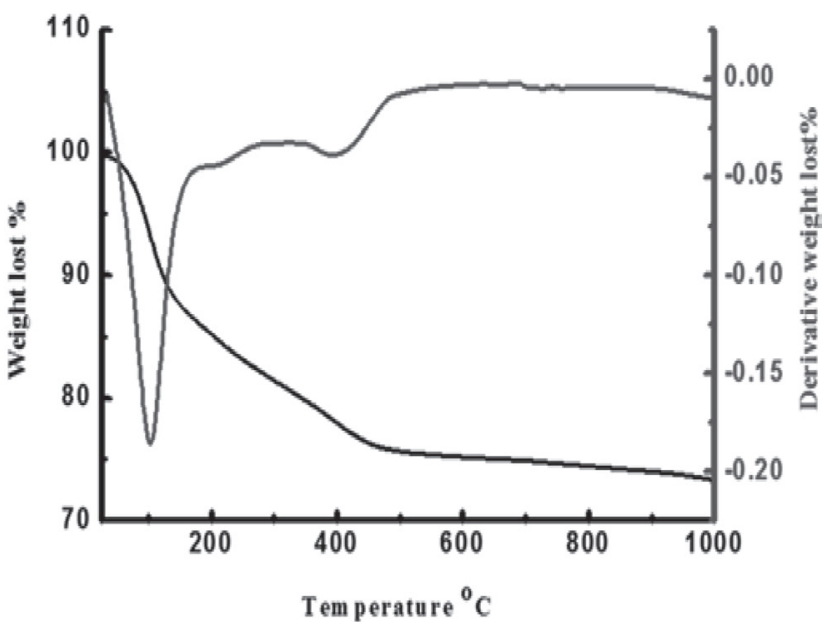

Fig. 3 TGA of uncalcined FMMZ catalyst.

which points out that, " the dispersed $\mathrm{Fe}_{2} \mathrm{O}_{3}$ and $\mathrm{MnO}$ particles along with $\mathrm{MoO}_{3}$ species lying on zirconia surface avoiding throughout the calcination process the generation of agglomerated form of them ${ }^{24)}$.

Generally, the strength and the density of energetic centres have been determined via temperature programmed desorption(TPD) technique. In addition, ammonia and pyridine have been employed as probe indicators for the evaluation of the acid strength and density of energetic centres for acidic heterogeneous catalysis systems.

According to the data obtained from ammonia TPD profile of the Fe-Mn- $\mathrm{MoO}_{3} / \mathrm{ZrO}_{2}$ catalyst, the total acidic sites density on surface of catalyst has been found to be around $2411.0 \mu \mathrm{mol} / \mathrm{g}$ as shown in Table 1.

TGA analysis of uncalcined FMMZ catalyst is depicted in Fig. 3. The loss of the mass obtained with thermogravimetric study profile consent comparatively with the resultant decomposition to the constituents of catalyst. The TGA profile of the FMMZ consists of two mass losses steps in temperature ranged mainly between 30.0-314 and 315.50$463.0^{\circ} \mathrm{C}$, respectively. The first decomposition point starts at about $30^{\circ} \mathrm{C}$ and ended at $314^{\circ} \mathrm{C}$ is due to the removal of physisorbed water, ammonia, nitrogen oxides, dehydroxylation process of $\mathrm{ZrO}(\mathrm{OH})_{2}$ and complete decomposition of metal salts to their free oxides (Ferric oxide, Manganese oxide and $\left.\mathrm{MoO}_{3}\right)^{25-27)}$. The second thermal decomposition phase begins at about $315.5^{\circ} \mathrm{C}$ reaching constant weight losses at about $463.0^{\circ} \mathrm{C}$. This step corresponds to solidsolid interaction between the metal oxides ${ }^{28}$. At the same time, the thermogram of FMMZ catalyst does not show any noticeable weight loss at a temperature more than $860^{\circ} \mathrm{C}$, which might be attributed to the presence of $\mathrm{Fe} / \mathrm{Mn} / \mathrm{Zr}$ oxide suppressing the evaporation of $\mathrm{MoO}_{3}$ at higher temperature $^{21-26)}$.

The BET surface area and average pore diameter of FMMZ catalyst obtained using BET method were $49.5 \mathrm{~m}^{2} / \mathrm{g}$ and $85.0 \mathrm{~nm}$, respectively. In correspondence to $5.8 \mathrm{~nm}$ which ascribes to a diameter of triglyceride, the pore size of ferric-manganese promoted molybdated zirconia catalyst was $85.0 \mathrm{~nm}$, therefore, triglyceride molecule could be easily inter through the pores of FMMZ and allowed the reactants to be in touch with active centres which improves catalytic activity.

In the meantime, the leaching of the prepared Ferricmanganese doped molybdated zirconia solid acid catalyst was determined by Shimadzu X-ray fluorescence (XRF) with a Rayny EDX-720 spectrometer since(EDS) the energy dispersive spectroscopy has been applied to study the elemental composition of the materials ${ }^{29,30)}$. Accordingly, the metallic constituent of $\mathrm{Fe}-\mathrm{Mn}-\mathrm{MoO}_{3} / \mathrm{ZrO}_{2}$ is presented in Table 2.

Figure 4 displays nanosized crystal shape in the FMMZ catalyst as characterized by TEM. It has been obvious that the FMMZ nanoparticles are in the order of tetragonal system with sizes in a limit of 5-10 nm having standard diameter of $\sim 6.2 \mathrm{~nm}$. Moreover, most of FMMZ nanoparticles have been connected to each other while the others are isolated implies the existence of electrostatic attraction and repulsion among FMMZ nanoparticles.

The Fe-Mn- $\mathrm{MoO}_{3} / \mathrm{ZrO}_{2}$ (FMMZ) sample displayed an emission peak around 530.0 electron volts assigned to $\mathrm{O} 1 \mathrm{~s}$ while the $182.5 \mathrm{eV}$ characteristic of $\mathrm{Zr} 3 \mathrm{~d} 5 / 2$. Thus, the emission line depicted in Fig. 5 (a) and (b) attributed to the

Table 2 Quantitative percentage of elements for the fresh and used $\mathrm{Fe}-\mathrm{Mn}-\mathrm{MoO}_{3} / \mathrm{ZrO}_{2}$ catalyst.

\begin{tabular}{lccc}
\hline \multicolumn{1}{c}{ Catalyst } & $\% \mathrm{Fe}_{2} \mathrm{O}_{3}$ & $\% \mathrm{MnO}$ & $\% \mathrm{MoO}_{3}$ \\
\hline Fresh & 2.354 & 0.558 & 4.161 \\
fourth run & 2.285 & 0.556 & 4.149 \\
Seventh run & 2.225 & 0.554 & 4.135 \\
\hline
\end{tabular}




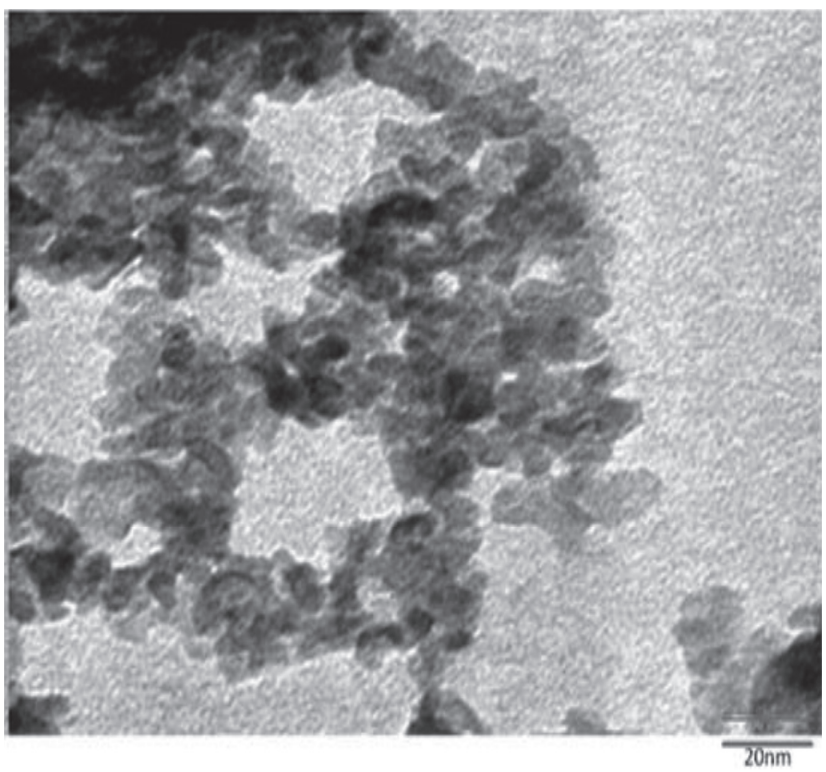

Fig. 4 TEM of Fe-Mn-promoted molybdenum oxide/ zirconia nanoparticles calcined at $600^{\circ} \mathrm{C}$ for $3 \mathrm{~h}$.

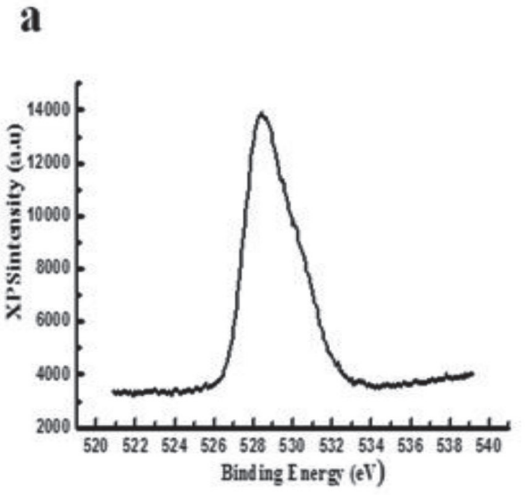

zirconia. Figure 5 (c) confirms the molybdenum emission peaks of Fe-Mn- $\mathrm{MoO}_{3} / \mathrm{ZrO}_{2}$ (FMMZ). In addition, the emission line at 233.2 and 235.8 electron volts match to emission peaks generated by $3 \mathrm{~d} 5 / 2$ and $3 \mathrm{~d} 3 / 2$ electrons of molybdenum, respectively. Nonetheless, the established significances of binding energy have been attributed to Mo $(+6)^{22)}$. Figure $5(\mathrm{~d})$ illustrates the photoelectron emission peaks of $\mathrm{Fe}(+3)-\mathrm{Mn}-\mathrm{MoO}_{3} / \mathrm{ZrO}_{2}$ (FMMZ) in ferric 2p zone. The ferric $2 \mathrm{p} 3 / 2$ and $2 \mathrm{p} 1 / 2$ photoelectron peaks were appeared at about 711.3 and $724.0 \mathrm{eV}$, respectively, which maintains the presence of ferric oxide on the $\mathrm{Fe}-\mathrm{Mn}-\mathrm{MoO}_{3} /$ $\mathrm{ZrO}_{2}$ surface. This band is apparent confirmation for existence of $\mathrm{Fe}^{+3}$ which basically matching to the data reported for ferric oxide ${ }^{31}$. Manganese emission had been identified simply through relatively noisy sign. Figure $5(\mathrm{e})$ depicts the XPS spectrum of Fe-Mn- $\mathrm{MoO}_{3} / \mathrm{ZrO}_{2}$ catalyst in $2 \mathrm{p}$ zone of manganese. Furthermore, $2 \mathrm{p} 3 / 2$ and $2 \mathrm{p} 1 / 2$ photoelectron peaks which appeared around 642.5 and $653.4 \mathrm{eV}$, respectively, indicated the existence of manganese oxide at the surface of the Fe-Mn- $\mathrm{MoO}_{3} / \mathrm{ZrO}_{2}$ catalyst. b

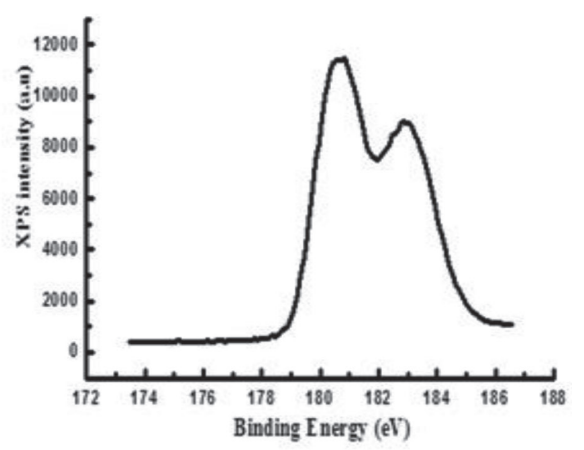

c

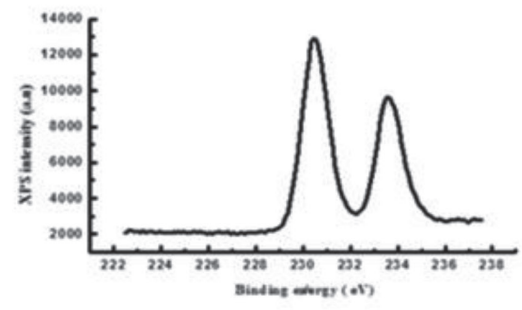

d

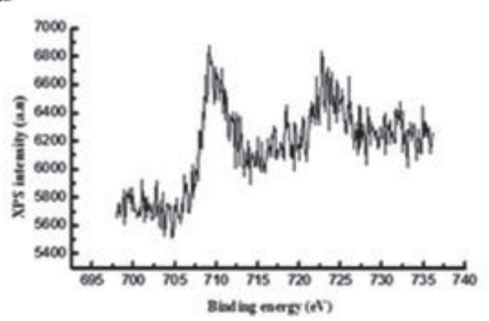

$\mathbf{e}$

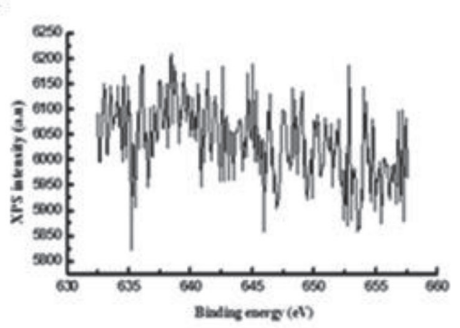

Fig. 5 XPS spectra of the Fe-Mn-MoO $/ \mathrm{ZrO}_{2}$ (FMMZ) (O Is, Zr 3d) (a-b), (Mo 3d, Fe 2p and Mn 2p) (c-e). 


\subsection{Catalytic Activity of Fe-Mn- $\mathrm{MoO}_{3} / \mathrm{ZrO}_{2}$ Catalyst}

3.2.1 Impact of Process Factors on the Esters Yield

The impact of different process parameters which includes temperature of the process, catalyst concentration (wt/wt\%), time and molar ratio of alcohol/waste cooking oil on the process employed to synthesize the biodiesel were appraised.

\subsubsection{The influence of temperature}

The temperature of the simultaneous process was recognised to be considerably influenced on the biodiesel yield ${ }^{32)}$. Thus, the experiments using the FMMZ nanoparticles solid acid catalyst were performed at $80^{\circ} \mathrm{C}$ up to, $220^{\circ} \mathrm{C}$ at interval of $20^{\circ} \mathrm{C}$. The product improved by raised

(a)

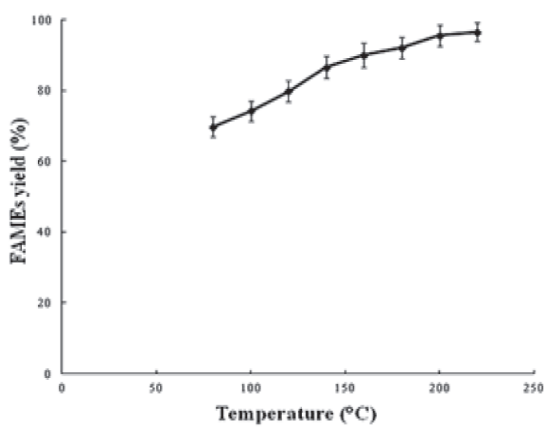

(c)

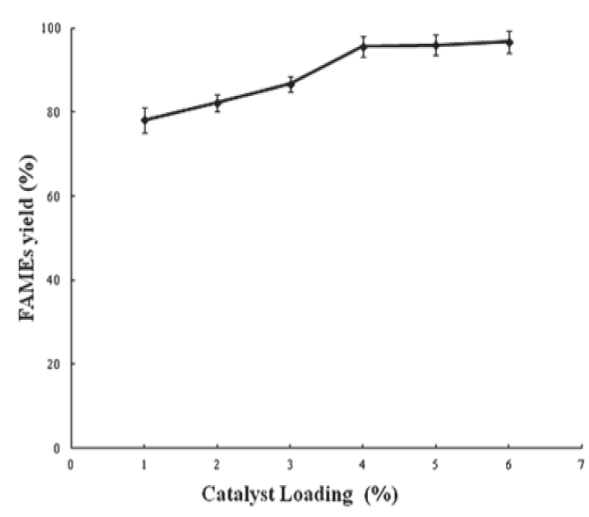

the simultaneous process temperature thus attained the maxima at around $200^{\circ} \mathrm{C}$ with negligible increased in yield at around $220^{\circ} \mathrm{C}$ as presented in Fig. $6(\mathrm{a})$. Therefore, the temperature of the process was optimized at $200^{\circ} \mathrm{C}$, for the additional study.

3.2.1.2 The Influence of Reaction Time

Figure $6(\mathrm{~b})$ shows the difference of produced biodiesel with duration of the process. At an optimized condition of the process, it has been seen that the biodiesel yield was low at first h. However, while the duration of the process rises the product has been improved gradually until the fourth $\mathrm{h}$ and subsequently kept almost persistent. The approximately process equilibrium had been attained about

(b)

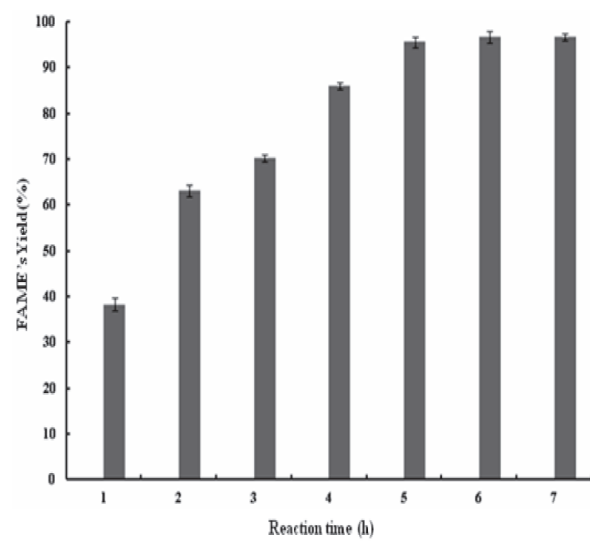

(d)

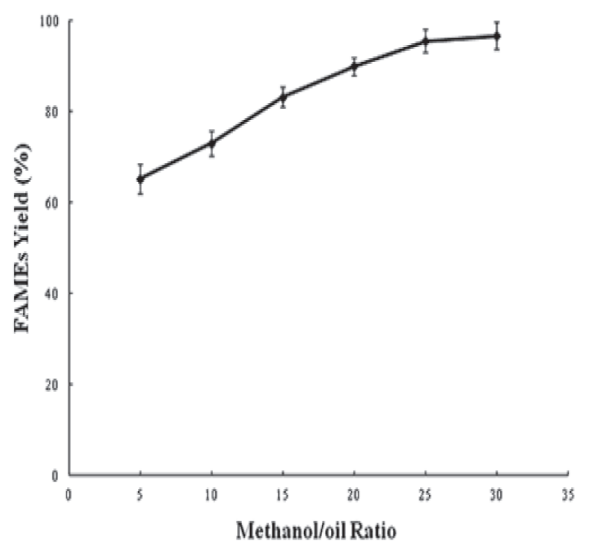

Fig. 6 Optimization of reaction parameters: (a) Impact of temperature of simultaneous process at $5 \mathrm{~h}$, loading of catalyst $4 \%$, molar ratio of spent cooking feedstock oil /methyl alcohol 1/25 and speed of mechanical mixer 600 rpm. (b) Impact of duration of the simultaneous process using 4\% amount of enhancer, ratio of methyl alcohol/ spent cooking feedstock $25 / 1$, temperature of the process $200^{\circ} \mathrm{C}$ and speed of mechanical mixer $600 \mathrm{rpm}$. (c) Impact of $\mathrm{Fe}(+3)-\mathrm{Mn}-\mathrm{MoO}_{3} / \mathrm{ZrO}_{2}$ loading throughout $5 \mathrm{~h}$, ratio of methyl alcohol/ spent cooking feedstock $25 / 1$, temperature of the process $200^{\circ} \mathrm{C}$ and speed of mechanical mixer $600 \mathrm{rpm}$. (d) Impact of the ratio of methyl alcohol/ spent cooking oil, during $5 \mathrm{~h}$, temperature of the methanolysis process $200^{\circ} \mathrm{C}$, speed of mechanical mixer $600 \mathrm{rpm}$ and catalyst dosage $4 \% \mathrm{wt} / \mathrm{w}$. 
$95.6 \%$ at $5 \mathrm{~h}$ of reaction time. Hence, $5 \mathrm{~h}$ were considered as an optimum reaction time for preparation of biodiesel employing spent cooking oil via nanoparticles ferric-manganese doped molybdated zirconia solid acid catalyst.

3.2.1.3 The influence of Catalyst Quantity

The catalyst quantity is key parameter that required optimization in order to enhance biodiesel quantity. Thus, higher amount of enhancer has been necessary in improving accessibility of energetic centres. Nevertheless, impact of $\mathrm{Fe}(+3)-\mathrm{Mn}-\mathrm{MoO}_{3} / \mathrm{ZrO}_{2}$ loading (1-6\% w/w) on WCOME's yield was evaluated utilizing the optimum condition of the process. As shown in Fig. 6 (c) rising loading of $\mathrm{Fe}(+3)-\mathrm{Mn}-\mathrm{MoO}_{3} / \mathrm{ZrO}_{2}$ which begins with $1 \%$ (wt/wt) till $6 \%$ (wt./wt) result in a clear enhance in the yield from 70 to $96 \%$. However, when the amount of the catalyst rose to $6 \%$ wt. the amount of WCOME's insignificantly improved. Therefore, the quantity of $\mathrm{Fe}(+3)-\mathrm{Mn}-\mathrm{MoO}_{3} / \mathrm{ZrO}_{2}$ catalyst have considerable impact on the quantity of WCOME's. Thus the optimum quantity of $\mathrm{Fe}(+3)-\mathrm{Mn}-\mathrm{MoO}_{3} / \mathrm{ZrO}_{2}$ is found to be $4 \% \mathrm{wt} / \mathrm{wt}$.

3.2.1.4 Influence of Molar ratio of Waste Cooking Feedstock / Methyl Alcohol

As far as the simultaneous methanolysis reaction for the synthesis of WCOME's is reversible, excess quantity of methyl alcohol wants to make the reaction towards the formation of WCOME's ${ }^{32)}$. In order to assess the impact of alcohol/waste cooking feedstock molar ratio on the quantity of WCOME's using FMMZ catalyst a series of experiments had been done employing spent cooking feedstock to methyl alcohol ratio in a range of (5-30) keeping other parameters at the optimum level. According to Fig. 6 (d), it has been clearly seen that, the transformation of spent cooking feedstock using FMMZ catalyst revealed a durable need on the spent cooking oil/ methyl alcohol molar ratio. However, once the dosage of methyl alcohol improved, consequently the product enhanced significantly thus the maximum yield found at dosage of $1 / 25$, further than this quantity has no noteworthy development in WCOME's yield so the extra methyl alcohol would be collected, hence reprocessed.

\subsection{The Effect of Ferric and Manganese-dopants on the Performance of Fe-Mn- $-\mathrm{MoO}_{3} / \mathrm{ZrO}_{2}$}

The consequence of ferric and manganese dopants on the surface of $\mathrm{Fe}-\mathrm{Mn}-\mathrm{MoO}_{3} / \mathrm{ZrO}_{2}$ were examined via the performance of the prepared solid acid catalysts (Zirconia, molybdated zirconia and ferric-manganese doped molybdated zirconia (FMMZ) for the preparation of biodiesel simultaneously. The comparative process was carried out at $5 \mathrm{~h}$, stoichiometric ratio of waste oil to methyl alcohol 1:25 with $4 \% \mathrm{wt} / \mathrm{wt}$. catalyst amount, temperature at $200^{\circ} \mathrm{C}$ and the $600 \mathrm{rpm}$ stirrer. As a result the experimental yield of methyl esters obtained from zirconia, molybdated zirconia and ferric-manganese doped molybdated zirconia was found to be $48.6 \pm 1.14,73.0 \pm 0.25$ and $95.6 \% \pm 0.15$, respectively. However, previously it had been reported that the methyl esters yield obtained via zirconia and molybdated zirconia only was found to be 49.3 and $65.0 \%$, respectively ${ }^{11-19)}$. In addition, Table 1 shows that ferric-manganese doped molybdated zirconia gives highest ester yield as well as specific surface area and density of active centres which indicates that the ferric and manganese dopants increase the surface area, acidity and thus the catalytic activity of ferric-manganese doped molybdated zirconia relative to that of zirconia and molybdated zirconia catalysts.

\subsection{Assessment of Reusability}

Reusability established as the major phase in manufacturing feasibility as it decreases the cost of biodiesel synthesis $^{33)}$. Thus, the recycling of the FMMZ catalyst for biodiesel synthesis has been considered for several runs after the purification step has been carried out using hexane and then alcohol to eliminate the unreacted triglyceride and the product stacked on the pores of FMMZ. Hence, FMMZ catalyst was finally dried at $120^{\circ} \mathrm{C}$ for six h. For the assessment of reusability, the reaction was performed under the optimized parameters of the methanolysis process. The consequences of a series of the methanolysis experiments have been displayed in Fig. 7. Accordingly, the product remains almost the same up to the sixth cycle and then drop to around $93.7 \%$ in the seventh run suggesting the successful reusability of the catalyst for six cycles. The decrease of WCOME's yield may be attributed to the slight leaching of iron and molybdenum and/or partial blockage of pores with oil. Therefore, it can be concluded that, the $\mathrm{Fe}-\mathrm{Mn}-\mathrm{MoO}_{3}-\mathrm{ZrO}_{2}$ catalyst is simply reused without any leaching of manganese and insignificant leaching of iron and molybdenum even after the seventh run as shown in Table 2.

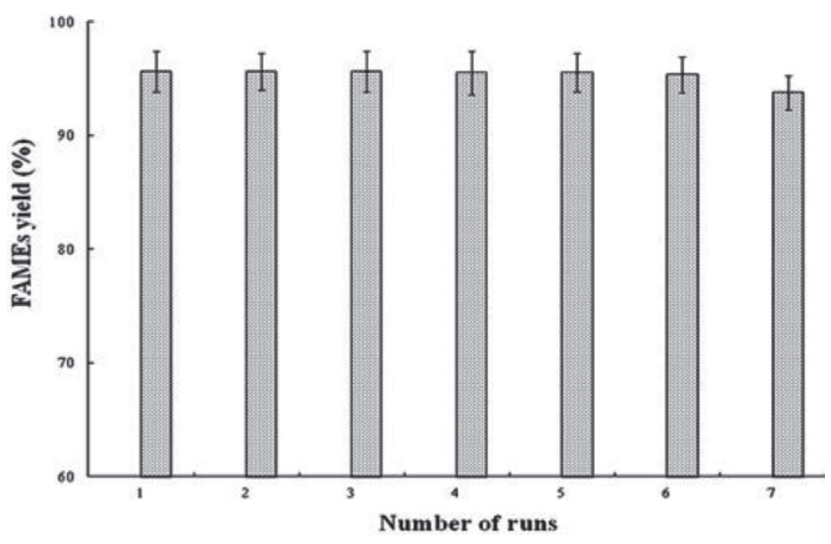

Fig. 7 Reusability of FMMZ nanoparticle catalyst calcined at $600^{\circ} \mathrm{C}$ for $3 \mathrm{~h}$. 


\subsection{The Determination of FAME's through GC Analysis}

The GC results showed that, waste cooking oil methyl esters has the lowest measurement of saturated lipid acids $(43.4 \%)$ compared to unsaturated fatty acids (52.2\%).

\subsection{Fuel Quality of Biodiesel Derived from Spent Cooking Oil}

The fuel characteristics (flash point, pour point (PP), pour point $(\mathrm{CP})$, kinematic viscosity $\left(40^{\circ} \mathrm{C}\right)$, and density) of produced WCOME's were determined, as depicted in Table 3 according to biodiesel ASTM $^{16-34)}$ standard methods. In appraisal to palm oil methyl esters $(\mathrm{POME})^{34)}$ from Malaysia and also diesel fuel, WCOME's demonstrated high gumminess value on $40^{\circ} \mathrm{C}\left(4.4 \mathrm{~mm}^{2} / \mathrm{s}\right.$ Table 5.3$)$; but WCOME's was surrounded by agreed American Society for Testing and Materials Standard No. $6751\left(1.9-6.0 \mathrm{~mm}^{2} / \mathrm{s}\right)$ kinematic viscosity conditions. However, the flash point of WCOME's and palm oil methyl esters was in the range of $\left(162^{\circ} \mathrm{C}\right.$ and $165^{\circ} \mathrm{C}$ ) which was greater than diesel fuel. On the other hand, WCOME's and POME $^{34)}$ revealed improved cloud point and power point compared to conventional diesel, whereas WCOME's executing better than $\mathrm{POME}^{34)}$. However, the density of WCOME's $(0.87 \mathrm{~kg} / \mathrm{L})$ was also found to be fit contained by the standards of American Society for Testing and Materials $\left(0.82-0.9 \mathrm{~g} / \mathrm{cm}^{3}\right)$ biodiesel standards Table 3.

\section{CONCLUSIONS}

Ferric-manganese promoted molybdenum oxide/zirconia (FMMZ) nanoparticles catalyst exhibited high porosity, specific surface area, thermal stability, good reusability and excellent catalytic performance via methanolysis transformation of used frying vegetable oil. WCOME's yield reached $95.6 \%$ at $5 \mathrm{~h}$ reaction, catalyst loading $4 \% \mathrm{w} / \mathrm{w}$, molar ratio of methanol to WCO 1:25 as molar ratio of methyl alcohol to used frying vegetable oil and $200^{\circ} \mathrm{C}$ and reduction of FFAs level closely to around $0.590 \%$ proof that the FMMZ is greatly operative to methanolysis conversion of waste cooking oil. Moreover, No considerable decrease in methyl esters yield had been detected subsequently six successive methanolysis process sets. In conclusion, FMMZ has potential for widespread applica- tions especially for industrial scale preparation of renewable fuel employing any acidic oil.

\section{ACKNOWLEDGEMENT}

The authors acknowledge the financial support of the International Graduate Research Fellowship (IGRF) from the Universiti Putra Malaysia. And also the first author would like to thank all rulers, members of the Supreme Council of the United Arab Emirates and to all people in Sudan and UAE.

\section{REFERENCES}

1) Liu, G.; Yan, B.; Chen, G. Technical review on jet fuel production. Renew. Sust. Energ. Rev. 25, 59-70 (2013).

2) Lotero, E.; Liu, Y.; Lopez, D. E.; Suwannakarn, K.; Bruce, D. A.; Goodwin Jr, J. G. Synthesis of biodiesel via acid catalysis. Ind. Eng. Chem. Res. 44, 5353-5363 (2005).

3) Al-Zuhair, S. Production of biodiesel: possibilities and challenges. Biofuels Bioprod. Biorefin. 1, 57-66 (2007).

4) Demirbaş, A. Biodiesel fuels from vegetable oils via catalytic and non-catalytic supercritical alcohol transesterifications and other methods: a survey. Energ. Convers. Manage. 44, 2093-2109(2003).

5) Vicente, G.; Martínez, M.; Aracil, J. Integrated biodiesel production: a comparison of different homogeneous catalysts systems. Bioresource Technol. 92, 297-305 (2004).

6) Zheng, S.; Kates, M.; Dube, M.; McLean, D. Acid-catalyzed production of biodiesel from waste frying oil. Biomass Bioenerg. 30, 267-272(2006).

7) Corma, A. Inorganic solid acids and their use in acidcatalyzed hydrocarbon reactions. Chem. Rev. 95, 559614 (1995).

8) Narasimharao, K.; Lee, A.; Wilson, K. Catalysts in production of biodiesel: a review. J. Biobased Mater.Bioenerg. 1, 19-30 (2007).

9) Kiss, F. E.; Jovanović, M.; Bošković, G. C. Economic

Table 3 Quality of biodiesel derived from used cooking vegetable oil.

\begin{tabular}{lcccc}
\hline \multicolumn{1}{c}{ Features } & WCOMEs & Conventional fuel & ASTM D 6751 & EN 14214 \\
\hline Cloud point $\left({ }^{\circ} \mathrm{C}\right)$ & $-5 \pm 1.25$ & - & - & - \\
Density $\left(\mathrm{g} / \mathrm{cm}^{3}\right)$ & $0.8780 \pm 0.005$ & 0.85 & $0.82-0.9$ & $0.86-0.90$ \\
Flash point $\left({ }^{\circ} \mathrm{C}\right)$ & $162 \pm 12.3$ & 68 & 130 minimum & 120 minimum \\
Kinematic viscosity $\left(\mathrm{mm}^{2} / \mathrm{s}\right)$ at $40^{\circ} \mathrm{C}$ & $4.4 \pm 1.5$ & 2.6 & $1.9-6.0$ & $3.5-5.0$ \\
Pour point $\left({ }^{\circ} \mathrm{C}\right)$ & $-10 \pm 1.9$ & - & - & - \\
\hline
\end{tabular}


and ecological aspects of biodiesel production over homogeneous and heterogeneous catalysts. Fuel Process. Technol. 91, 1316-1320 (2010).

10) Serio, M. D.; Cozzolino, M.; Tesser, R.; Patrono, P.; Pinzari, F.; Bonelli, B.; Santacesaria, E. Vanadyl phosphate catalysts in biodiesel production. Appl. Catal. A: Gen. 320, 1-7(2007).

11) Jacobson, K.; Gopinath, R.; Meher, L. C.; Dalai, A. K. Solid acid catalyzed biodiesel production from waste cooking oil. Appl. Catal. B: Environ. 85, 86-91 (2008).

12) Santos, V. C.; Bail, A.; Okada, H. d. O.; Ramos, L. P.; Ciuffi, K. J.; Lima, O. J.; Nakagaki, S. Methanolysis of soybean oil using Tungsten-containing heterogeneous catalysts. Energ. Fuel 25, 2794-2802 (2011).

13) Alhassan, F. H.; Rashid, U.; Yunus, R.; Sirat, K.; Ibrahim, L. M.; Taufiq-Yap, Y. Synthesis of ferric-manganese doped tungstated zirconia nanoparticles as heterogeneous solid superacid catalyst for biodiesel production from waste cooking oil. Int. J. Green Energ. DOI: 10.1080/15435075.2014.880843(2014).

14) Alhassan, F. H.; Yunus, R.; Rashid, U.; Sirat, K.; Islam, A.; Lee, H. V.; Taufiq-Yap, Y. H. Production of biodiesel from mixed waste vegetable oils using Ferric hydrogen sulphate as an effective reusable heterogeneous solid acid catalyst. Appl. Catal. A: Gen. 456, 182-187 (2013).

15) American Oil Chemists' Society(AOCS), Official methods and recommended practices of the AOCS, USA, 1997.

16) Fatah, H. Alhassan; Umer Rashid; Y.H. Taufiq-Yap. Synthesis of waste cooking oil-based biodiesel via effectual recyclable bi-functional $\mathrm{Fe}_{2} \mathrm{O}_{3}-\mathrm{MnO}-\mathrm{SO}_{4}{ }^{2-} / \mathrm{ZrO}_{2}$ nanoparticle solid catalyst. Fuel 142, 38-45 (2015).

17) Alhassan, F. H.; Rashid, U.; Taufiq-Yap, Y. H. FerricManganese Doped Sulphated Zirconia Nanoparticle Catalyst for Single-Step Biodiesel Production from Waste Cooking Oil: Characterization and Optimization. Int. J. Green Energ. DOI: 10.1080/15435075.2014. 966267 (2014).

18) Tan, K. T.; Lee, K. T.; Mohamed, A. R. A glycerol-free process to produce biodiesel by supercritical methyl acetate technology: An optimization study via response surface methodology. Bioresource Technol. 101, 965-969 (2010).

19) Jitputti, J.; Kitiyanan, B.; Rangsunvigit, P.; Bunyakiat, K.; Attanatho, L.; Jenvanitpanjakul, P. Transesterification of crude palm kernel oil and crude coconut oil by different solid catalysts. Chem. Eng. J. 116, 61-66 (2006).

20) Calafat, A.; Avilán, L.; Aldana, J. The influence of preparation conditions on the surface area and phase formation of $\mathrm{MoO}_{3} / \mathrm{ZrO}_{2}$ catalysts. Appl. Catal. A: Gen. 201, 215-223 (2000).
21) El-Sharkawy, E.; Khder, A.; Ahmed, A. Structural characterization and catalytic activity of molybdenum oxide supported zirconia catalysts. Micropor. Mesopor. Mater. 102, 128-137(2007).

22) Chary, K. V. R.; Reddy, K. R.; Kishan, G.; Niemantsverdriet, J. W.; Mestl, G. Structure and catalytic properties of molybdenum oxide catalysts supported on zirconia. J. Catal. 226, 283-291(2004).

23) Khder, A.; El-Sharkawy, E.; El-Hakam, S.; Ahmed, A. Surface characterization and catalytic activity of sulfated tin oxide catalyst. Catal. Commun. 9, 769-777 (2008).

24) Jogalekar, A.; Jaiswal, R.; Jayaram, R. Activity of modified $\mathrm{SnO}_{2}$ catalysts for acid-catalysed reactions. $J$. Chem. Technol. Biotechnol. 71, 234-240 (1998).

25) Bi, M.; Li, H.; Pan, W.-P.; Lloyd, W. G.; Davis. B. H. Thermal studies of metal promoted sulfated zirconia. Am. Chem. Soc. Div. Fuel Chem. 41, 77-81(1996).

26) Shaheen, $\mathrm{W}$. Thermal behaviour of pure and binary $\mathrm{Fe}$ $\left(\mathrm{NO}_{3}\right)_{3} \cdot 9 \mathrm{H}_{2} \mathrm{O}$ and $\left(\mathrm{NH}_{4}\right)_{6} \mathrm{Mo}_{7} \mathrm{O}_{24} \cdot 4 \mathrm{H}_{2} \mathrm{O}$ systems. Mater. Sci. Eng. A, 445, 113-121 (2007).

27) Alhassan, F. H.; Rashid, U.; AL-Qubaisi, M. S.; Rasedee, A.; Taufiq-Yap, Y. H. The effect of sulphate contents on the surface properties of iron-manganese doped sulphated zirconia catalysts. Powder Technol. 253, 809813(2014).

28) Maiti, G.; Malessa, R.; Baerns, M. Studies on the reduction of the $\mathrm{Fe}_{2} \mathrm{O}_{3} / \mathrm{MoO}_{3}$ system and its interaction with synthesis gas $\left(\mathrm{CO}+\mathrm{H}_{2}\right)$. Thermochim. Acta 80, 11-21 (1984).

29) Zhang, L.; Yang, J.; Zhu, J.; Liu, Z.; Li, B.; Hu, T.; Dong, B. Properties and liquefaction activities of ferrous sulfate based catalyst impregnated on two Chinese bituminous coals. Fuel 81, 951-958(2002).

30) Yang, L.; Zhang, A.; Zheng, X. Shrimp shell catalyst for biodiesel production. Energ. Fuel 23, 3859-3865 (2009).

31) Scheithauer, M.; Bosch, E.; Schubert, U. A.; Knözinger, H.; Cheung, T.-K.; Jentoft, F. C.; Gates, B. C.; Tesche, B. Spectroscopic and microscopic characterization of Iron and/or Manganese-promoted sulfated zirconia. $J$. Catal. 177, 137-146 (1998).

32) Talebian-Kiakalaieh, A.; Amin, N. A. S.; Mazaheri, H. A review on novel processes of biodiesel production from waste cooking oil. Appl. Energ. 104, 683-710 (2013).

33) Fatah, H. Alhassan; Rashid, U.; Y. H. Taufiq-Yap. Biodiesel Synthesis Catalysed by Transition Metal Oxides: Ferric-Manganese Doped Tungstated/Molybdena Nanoparticle Catalyst. J. Oleo Sci. doi: 10.5650/jos. ess14161(2015).

34) Rashid, U.; Anwar, F. Production of biodiesel through optimized alkaline-catalyzed transesterification of rapeseed oil. Fuel 87, 265-273(2008). 